\title{
Endometrium Kanseri Radyoterapisinde Alan Dışı Meme Dozlarının TLD ile Dozimetrik Olarak İncelenmesi
}

\author{
Gökçen İnan ${ }^{1 *}$, Osman Vefa Gül ${ }^{2}$, Hamit Başaran ${ }^{3}$ \\ 1* Selçuk Üniversitesi, Tıp Fakültesi, Radyasyon Onkolojisi, Konya, Türkiye, (ORCID: 0000-0003-2995-0256), gokceninan85@gmail.com \\ ${ }^{2}$ Selçuk Üniversitesi, Tıp Fakültesi, Radyasyon Onkolojisi, Konya, Türkiye (ORCID: 0000-0002-6773-3132), vefagul@selcuk.edu.tr \\ ${ }^{3}$ Selçuk Üniversitesi, Tıp Fakültesi, Radyasyon Onkolojisi, Konya, Türkiye (ORCID: 0000-0002-2122-8720), drhbasaran@gmail.com
}

(İlk Geliş Tarihi 27 August 2021 ve Kabul Tarihi 10 November 2021)

(DOI: $10.31590 /$ ejosat.987094)

ATIF/REFERENCE: İnan, G., Gul, O.V. \& Başaran, H. (2021). Endometrium Kanseri Radyoterapisinde Alan Dışı Meme Dozlarının TLD ile Dozimetrik Olarak İncelenmesi. Avrupa Bilim ve Teknoloji Dergisi, (27), 818-822.

$\ddot{O} \mathbf{z}$

Radyoterapi alan hastalarda tedavi bölgesi dışında uzak organlarda istenmeyen dozlar meydana gelmektedir. Bu dozlar tedavi planlama sistemi (TPS) tarafindan doğru olarak hesaplanmayabilir. Bu çalışma endometrium kanseri nedeniyle radyoterapi alan gerçek bir hastayı taklit eden bir fantom üzerinde alan içi alan konformal radyoterapi (FIF) ve yoğunluk ayarlı radyoterapi (YART) tekniklerinde termolüminesans dozimetre (TLD) kullanılarak alan dışı dozları ölçmeyi amaçlamaktadır. Alderson kadın rando fantom üzerinde endometrium bölgesi hedef tedavi hacmi olarak seçilmiştir. Alderson Rando fantom simüle edilerek ve 25 fraksiyonda 45 Gy ile Varian DHX lineer hızlandırıcıda üç farklı teknikde planlar oluşturulmuştur (FIF, 5A-YART, 7A-YART). Fantomda meme hacmi içerisine TLD-100 dozimetreleri yerleştirildikten sonra fantom ışınlanmıştır. Her bir teknik için elde edilen doz ölçümleri TPS dozları ile karşılaştırılmıştır. Sağ memenin TLD doz ölçümlerinin ortalaması FIF, 5A-YART ve 7A-YART teknikleri için sırasıyla $20.60 \pm 0.26$ cGy, 23.32 \pm 0.16 cGy ve 27.11 \pm 0.28 cGy olarak ölçülmüştür. Sol memenin TLD doz ölçümlerinin ortalamas1 FIF, 5A-YART ve 7AYART teknikleri için sırasıyla $20.17 \pm 0.13$ cGy, $22.35 \pm 0.18$ cGy ve $26.13 \pm 0.10$ cGy olarak bulunmuştur. Sağ ve sol meme için TPS den alınan ortalama doz değerleri 0 cGy olarak bulunmuştur. Sağ meme ve sol meme ortalama doz değerlerinde 5A-YART ve 7AYART teknikleri için anlamlı fark bulunmuştur $(\mathrm{p}=0.000)$. Meme gibi radyasyona duyarlı dokular radyoterapi tedavisinde alan dışı dozdan etkilenebilmektedir. Endometrium kanseri radyoterapinde en uygun tedavi tekniği seçilirken alan dişı dozlara dikkat edilmesi tedaviye pozitif katkı sağlayacaktır.

Anahtar Kelimeler: Alan dışı doz, Endometrium kanseri, Termolüminesans dozimetre

\section{Dosimetric Investigation of Out-of-Field Breast with TLD in Endometrial Cancer Radiotherapy}

\begin{abstract}
Unwanted doses may occur in distant organs, outside of the region where we want to be irradiated in patients treated with radiotherapy. These doses may not be accurately calculated by the treatment planning system (TPS). This study aims to measure outof-field doses using thermoluminescence dosimetry (TLD) in field in field conformal radiotherapy (FIF) and intensity modulated radiotherapy (IMRT) techniques on a phantom imitating the real patient receiving radiotherapy for endometrial cancer. Endometrium region on Alderson female rando phantom was selected as the target treatment volume. Plans were created by simulating the Alderson Rando phantom and using three different techniques (FIF, 5A-IMRT, 7A-IMRT) in a Varian DHX linear accelerator with 45 Gy in 25 fractions After TLD-100 dosimeters were placed in the breast volume in the phantom, the phantom was irradiated. TLD dose measurements obtained for each technique and TPS doses were compared. The mean TLD dose measurements of the right breast were measured as $20.60 \pm 0.26 \mathrm{cGy}, 23.32 \pm 0.16 \mathrm{cGy}$, and $27.11 \pm 0.28 \mathrm{cGy}$ for the FIF, 5A-IMRT, and 7W-IMRT techniques, respectively. The mean TLD dose measurements of the left breast were found to be $20.17 \pm 0.13 \mathrm{cGy}, 22.35 \pm 0.18 \mathrm{cGy}$, and $26.13 \pm 0.10 \mathrm{cGy}$ for the FIF, 5A-IMART, and 7A-IMRT techniques, respectively. The mean dose values obtained from TPS for the right and left breasts were found to be $0 \mathrm{cGy}$. A significant difference was found in the mean dose values of the right breast and left breast for the 5A-IMRT and 7A-IMRT techniques $(\mathrm{p}=0.000)$. Radiation-sensitive tissues such as the breast may be affected by out-of-field dose in radiotherapy treatment. When choosing the most appropriate treatment technique in endometrial cancer radiotherapy, paying attention to out-offield doses will make a positive contribution to the treatment.
\end{abstract}

Keywords: Out of field dose, Endometrim cancer, Thermoluminescence dosimeter.

\footnotetext{
*Sorumlu Yazar: gokceninan85@gmail.com
} 


\section{Giriş}

Endometrium kanseri gelişmiş ülkelerde yaygın olarak görülen jinekolojik kanserlerdendir. Radyoterapi tedavisi endometrium kanserinde önemli bir rol oynamaktadır (1). Radyoterapi tedavi planlamasının amacı, kritik organları ve sağlıklı dokuları koruyarak hedef hacme en iyi doz konformasyonunu sağlamaktır $(2,3)$. İyonlaştırıcı radyasyonun kanser hastalıklarının tedavisi için kullanımı, hastanın sağ kalımı arttıkça ve yeni tedavi teknikleri ortaya çıktıkça sürekli olarak gelişmektedir (4). Radyoterapide hedef hacim dişında kalan sağlıklı dokular istenmeyen dozlar alabilmektedir. Radyoterapi gören hastalar, birincil ışından alan içi dozları ve aynı zamanda 1şın hattında ve hasta içinde üretilen ikincil radyasyondan kaynaklanan alan dışı dozları da almaktadırlar (5). Alan dışı dozlar; kaynak cilt mesafesi (SSD), alan boyutları, 1şınlanan yapının derinliği, tedavide kullanılan foton enerjisi, ölçüm yapılan alan dişındaki noktanın lateral pozisyonu ve bu noktanın ışın eksenine uzaklığına bağlıdır (6). Alan dışı saçılan radyasyon, düşük enerjili, yumuşak X-1şını radyasyonu ve elektron kontaminasyonu kaynaklarından gelen düşük doz radyasyonun tüm vücuda maruz kalması nedeniyle tedavi sırasında bir endişe kaynağı oluşturmaktadır (7).

Tedavi planlama sistemi (TPS) hedef hacim içerisinde dozu doğru bir şekilde hesaplayabildiği hacimlerin ötesinde iç saçılma ve sızıntıdan doz alan kritik dokular bulunmaktadır (8). Alan dışı organ dozları, tıpkı saha içi organlarda olduğu gibi ikinci kanser riskini azaltmak için yönetilmelidir, ancak ikincil radyasyondan kaynaklanan alan dışı dozlar, genellikle klinik TPS hesaplanmaz, çünkü bu dozlar saha içi dozlardan daha düşüktür. Ayrıca, TPS doğruluğu genellikle alan kenarının dışında birkaç santimetre ile sınırlıdır (9). Düşük dozlarda radyasyona maruz kalma durumunda; genetik değişiklikler, karsinojen etki, ömür kısalması, aplastik anemi ve katarakt oluşumu gibi etkiler radyasyonun geç etkileridirler ve başlıca sağlık risklerini oluştururlar (10).

Çalışmamızda endometrium kanserlerinin FIF, 5A-YART ve 7A-YART teknikleri ile radyoterapisinde alan dışındaki sağlıklı dokulardan olan, sağ ve sol memenin aldığı dozun dozimetrik olarak incelenmesi amaçlanmaktadır. İnsan eşdeğeri Rando fantomda TLD ile ölçülen sağ ve sol meme dozları, TPS'den elde edilen doz değerleri ile karşılaştırılacaktır

\section{Materyal ve Metot}

\subsection{Alderson Rando Fantomun Hazırlanması ve Konturlaması}

Çalışmamızda kullanılan Alderson Rando fantom gerçek insan eşdeğeridir. Doku yoğunluğu $0.975 \mathrm{gr} / \mathrm{cm}^{3}$ ve akciğerlerin yoğunluğu 0.25-0.3 gr/ $\mathrm{cm}^{3}$ tür (11). Alderson Rando fantom Toshiba marka bilgisayarlı tomografi (BT) cihazına şeffaf baş altı yastık kullanılarak supin olarak yatırılmıştır. Endometrium bölgesi tedavi alanı olacak şekilde referans noktaları belirlenerek $2.5 \mathrm{~mm}$ kalınlıkta kesitler oluşturacak şekilde BT görüntüleri çekilmiştir. BT'den elde edilen görüntüler tedavi planlama sistemine (TPS) aktarılmıştır. Gross Tümör Hacim (GTV), Klinik Hedef Hacim (CTV) ve Planlanan Hedef Hacim (PTV) gibi hedef hacimler, Uluslararası Radyasyon Üniteleri ve Ölçümleri Komisyonu (ICRU) 83' de tanımlanan kriterlere göre tanımlanmıştır (12). Kritik organlar olarak mesane, rektum, bağırsak, sağ ve sol femur başları konturlanmıştır. Bütün konturlama işlemleri tek bir radyasyon onkoloğu tarafindan tanımlanmıştır.

\subsection{Tedavi planlama}

Çalışmamızda Eclipse V.15.1 TPS kullanılarak oluşturulan FIF, 5A-YART ve 7A-YART planlarının doz hesaplamalarında "Anisotropic Analytical Algorithm, AAA" algoritmas kullanılmıştır. Tedavi dozu 45 Gy (1.8 Gy x 25 fraksiyon) olarak belirlenmiştir. FIF planlarında, $18 \mathrm{MV}$ X-1şını kullanılarak 4 alan box tekniğinde ışın açıları olarak $0^{\circ}, 90^{\circ}, 180^{\circ}$ ve $270^{\circ}$, lik açılar kullanılmıştır. Belirlenen alanlar kopyalanmış ve çizdirilen sıcak doz bölgeleri kapatılarak yeniden hesaplatılmıştır. YART planları tersten planlama (inverse planning) yöntemiyle $6 \mathrm{MV}$ $\mathrm{X}$-1şını kullanılarak hazırlanmıştır. YART tekniğinde, 5A-YART planı $0^{\circ}, 72^{\circ}, 144^{\circ}, 216^{\circ}$ ve $288^{\circ}$ 'lik açılar kullanılarak sanal plan oluşturulmuştur. 7A-YART planında ise $0^{\circ}, 52^{\circ}, 104^{\circ}, 156^{\circ}$, $204^{\circ}, \quad 256^{\circ}$ ve $308^{\circ}$ lik açılar kullanılmıștır. Planlar oluşturulurken hedef hacimlere minimum ve maksimum doz sinırlamaları yapılarak PTV' nin \%95' inin tanımlanan dozun \%100' ünü alması hedeflenmiştir. Risk altındaki organlara belirlenen kriterler arasında en düşük dozu verebilmek için gerekli doz sınırlamaları yapılmıştır.

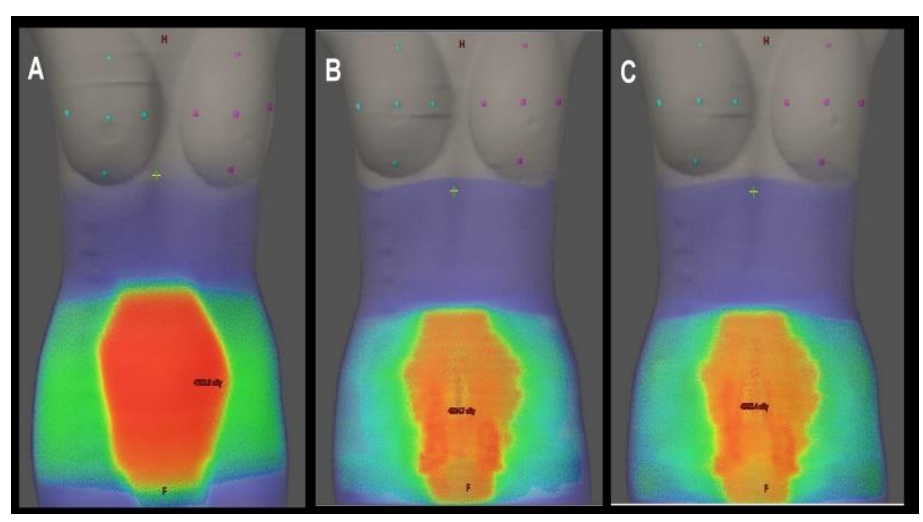

Şekil 1. Rando fantom içerisindeki TLD konumları

\subsection{TLD kalibrasyonu}

TLD dozimetrelerin üretimleri sırasında farklı miktarlarda katkılanmaları nedeniyle tuzak yapıları farklıdır bu nedenle; tuzak yapılarının farklı olmasından kaynaklanan duyarlılık farlılıklarının ortadan kaldırılması amacıyla kalibrasyon yapılmalıdır. $\mathrm{Bu}$ çalışmada $3.2 \mathrm{~mm} \quad \mathrm{x} \quad 3.2 \mathrm{~mm} \quad \mathrm{x} \quad 0.9 \mathrm{~mm}$ boyutlarında çip şeklinde doğal lityum florüre (LiF) Mg ve Ti ile katkılandırılmasılyla elde edilmiş olan TLD-100 dozimetreleri kullanılmıştır. TLD dozimetreler aynı zamanda ışınlama kalibrasyon öncesi tavlama işlemi yapılmalıdır. Tavlama işlemi ışınlama sonrası kalan radyasyonun silinmesi tüm tuzakların boşatılması TLD hassasiyeti açısından önemlidir. 60 adet LiF:Mg,Ti (TLD 100) dozimetreler firında $400^{\circ} \mathrm{C}$ 'de 1 saat ardından $100^{\circ} \mathrm{C}$ 'de 2 saat tavlanmıştır. Tüm mevcut TLD'ler, her birine isim verilerek kalibrasyon ve doz ölçüm işlemleri yapılmıştır. 60 adet TLD çipinden sapması fazla olanlar elenmiştir. Relatif standart sapması $\% \mp 1$ ' in altında olan yani doz cevapları birbirine yakın olan 60 TLD çipi çalışma için seçilmiş ve kullanılmak üzere kalibrasyonu yapılmıştır. TLD’ler Varian DHX lineer hızlandırıcı cihazı ve bolus kullanılarak 10 cm x 10 alanda, SSD $100 \mathrm{~cm}$ (kaynak cilt mesafesi) ve yüzeyden $1,5 \mathrm{~cm}$ derinlikte her bir dozimetre 1Gy olacak şekilde ışınlanmıştır. Her tedavi planlamasından sonra TLD' ler 
yerlerinden çıkartılarak ölçümleri yapılmıştır. TLD' lerin okunma işlemine geçmeden önce kararsız tuzaklardan kaynaklanan lüminesans sinyallerini gidermek amaciyla ön ısıtma işlemi firında $100^{\circ} \mathrm{C}$ 'de $10 \mathrm{dk}$ süreyle bekletilmiştir. TLD' lerin doz ölçüm işlemi bölümümüzde bulunan dozimetri laboratuvarında Harshaw marka 3500 model TLD okuyucu kullanılarak yapılmıştır.

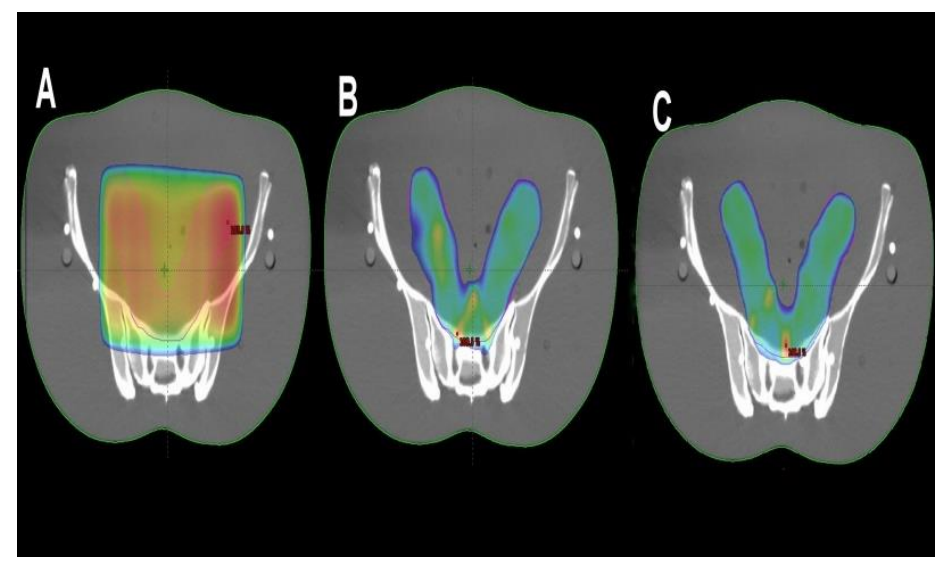

Şekil 2. A:FIF tekniği için doz dağılımı, B: 5A-YART tedavi tekniği için doz dağılımı, C: 7A-YART tedavi tekniği için doz dağılımı

\subsection{Alan Dışı Dozların TLD ile Ölçülmesi}

Alan dışı dozların TLD ile ölçülmesi için TPS' de Alderson rando fantom üzerinde sanal olarak hazırlanan FIF, 5A-YART ve 7A-YART planları, Varian DHX tedavi cihazına aktarılmıştır. Alderson rando fantomun hedef hacimden $18 \mathrm{~cm}$ alan dişı uzaklıkta bulunan her iki memesi için sol, sağ, üst, alt ve merkezinde olmak üzere 5 farklı noktaya TLD rodları yerleştirilmiştir. Rando fantom içerisindeki TLD konumları Şekil 1.de gösterilmiştir. Her bir noktaya üçer adet TLD yerleştirilmiştir. TLD' ler arasında hava kalmasını engellemek amacıyla rando fantom ile aynı malzemeden yapılmış doku eşdeğeri tıpalar kullanılmıştır. Ölçümler FIF, 5A-YART ve 7AYART planları için üçer defa tekrarlanarak yapılmıştır. Ölçümler sonrasında her iki meme için farklı noktalardan TLD ile ölçülen doz değerlerinin ortalamaları alınmıştır. Elde edilen ortalamalar 25 fraksiyon sonucunda bu bölgelerin aldığı dozlara ulaşmak için 25 ile çarpılarak sonuçlar hesaplanmıştır. Belirlenen noktalardaki absorbe dozlar okunarak TPS' den elde edilen doz değerleri ile karşılaştırılmıştır.

\section{5. İstatistiksel Analiz}

Tüm veriler Sosyal Bilimler için İstatistiksel Paket (SPSS) yazılımında (sürüm 25.1, IBM) kaydedildi ve analiz edildi. Tedavi planları arasındaki ilişkiyi değerlendirmek için One-Way Anova kullanılmıştır. $\mathrm{p}<0.05$ istatistiksel olarak anlamlı kabul edildi.

Tablo 1. Varian DHX tedavi cihazında 1şınlanan TLD' lerin ortalama doz ölçüm değerleri ile Eclipse TPS' de hesaplan doz değerleri

\begin{tabular}{|c|c|c|c|c|c|}
\hline Konum & & $\begin{array}{l}\text { FIF } \\
\text { (cGy) }\end{array}$ & $\begin{array}{l}5 \text { YART } \\
\text { (cGy) }\end{array}$ & $\begin{array}{l}7 \text { YART } \\
\text { (cGy) }\end{array}$ & $\begin{array}{l}\text { TPS } \\
\text { (cGy) }\end{array}$ \\
\hline \multirow[t]{6}{*}{ Să̆ meme } & Sol & $19.65 \pm 0.37$ & $20.91 \pm 0.97$ & $24.51 \pm 0.57$ & 0 \\
\hline & Sağ & $22.59 \pm 0.80$ & $25.98 \pm 0.62$ & $24.76 \pm 0.25$ & 0 \\
\hline & Üst & $10.70 \pm 0.33$ & $12.35 \pm 0.15$ & $15.58 \pm 0.12$ & 0 \\
\hline & Alt & $31.09 \pm 0.38$ & $37.84 \pm 0.21$ & $41.72 \pm 0.46$ & 0 \\
\hline & Merkez & $18.98 \pm 0.71$ & $19.51 \pm 0.40$ & $28.98 \pm 1.39$ & 0 \\
\hline & Ortalama doz & $20.60 \pm 0.26$ & $23.32 \pm 0.16$ & $27.11 \pm 0,28$ & 0 \\
\hline \multirow[t]{6}{*}{ Sol meme } & Sol & $18.46 \pm 0.15$ & $20.82 \pm 0.41$ & $22.80 \pm 0.48$ & 0 \\
\hline & Sağ & $18.71 \pm 0.33$ & $19.69 \pm 0.11$ & $24.73 \pm 0.31$ & 0 \\
\hline & Üst & $10.66 \pm 0.22$ & $11.46 \pm 0.58$ & $14.55 \pm 1.06$ & 0 \\
\hline & Alt & $29.25 \pm 0.35$ & $34.58 \pm 0.62$ & $38.30 \pm 0.21$ & 0 \\
\hline & Merkez & $23.80 \pm 0.48$ & $25.18 \pm 0.42$ & $30.28 \pm 0.57$ & 0 \\
\hline & Ortalama doz & $20.17 \pm 0.13$ & $22.35 \pm 0.18$ & $26.13 \pm 0.10$ & 0 \\
\hline
\end{tabular}

\section{Araştırma Sonuçları ve Tartışma}

\subsection{Bulgular}

FIF, 5A-YART ve 7A-YART ile yapilan planlara ait doz dağılımları Şekil 2. de gösterilmiştir. TPS' de oluşturulan üç farklı plan için planlanan hedef hacim, risk altındaki organlar (mesane, rektum, sağ femur, sol femur ve bağırsak), konformalite indeks (CI) ve homojenite indeks (HI) Tablo 2.' de verilmiştir. Buna göre; PTV için 7A-YART tekniği FIF ve 5AYART tekniklere göre daha üstün bulunmuştur. CI değeri FIF, 5A-YART ve 7A-YART planlama teknikleri için sırasıyla, 1.85, 0.83 ve 0.89 olarak bulunmuştur. FIF tekniği için HI değeri 0.05 iken diğer iki teknik için sırasıyla 0.09 ve 0.08 olarak bulunmuştur. Mesane ve rektumun $\mathrm{D}_{\text {ort }}, \mathrm{V}_{30}, \mathrm{~V}_{45}$ ve $\mathrm{V}_{50}$ değerleri için 7A-YART tekniği diğer tedavi tekniklerine göre üstün bulunmuştur. Sağ femur ve sol femurun $\mathrm{D}_{\text {ort }}, \mathrm{V}_{20}$ değerleri için e-ISSN: 2148-2683
7A-YART tekniği diğer tedavi tekniklerine göre üstün bulunmuştur. Ayrıca 7A-YART tekniği bağırsak $D_{\text {ort }}$ değeri için daha iyi koruma sağlamaktadır. FIF, 5A-YART ve 7A-YART tedavi tekniklerinde her iki meme için TPS ve TLD ortalama doz değerleri Tablo II' de verilmiştir. Sağ ve sol meme için TPS' den alınan ortalama doz değerleri 0 cGy olarak bulunmuştur. Sağ memenin TLD doz ölçümlerinin ortalaması FIF, 5A-YART ve 7A-YART teknikleri için sırasıyla $20.60 \pm 0.26$ cGy, $23.32 \pm 0.16$ cGy ve $27.11 \pm 0.28$ cGy olarak ölçülmüştür. Sol memenin TLD doz ölçümlerinin ortalaması FIF, 5A-YART ve 7A-YART teknikleri için sirasıyla $20.17 \pm 0.13$ cGy, $22.35 \pm 0.18$ cGy ve $26.13 \pm 0.10$ cGy olarak bulunmuştur. FIF ve 5A-YART teknikleri arasında anlamlı fark görülmüş olup, sağ ve sol meme ortalama doz değerleri için anlamlı olarak bulunmuştur $(\mathrm{p}=0.000)$. FIF ve 7A-YART teknikleri arasında anlamlı fark gözlenmiş olup sağ meme ve sol meme ortalama doz değerleri için anlamlı olarak bulunmuştur $(\mathrm{p}=0.000)$. 
Tablo 2. TPS' de PTV ve kritik organ doz değerleri

\begin{tabular}{llccc}
\hline Parametreler & & FIF & 5 A & 7 A \\
\hline PTV & $\mathrm{D}_{98}(\mathrm{cGy})$ & 4414 & 4445 & 4449 \\
& $\mathrm{D}_{95}(\mathrm{cGy})$ & 4400 & 4423 & 4450 \\
& $\mathrm{D}_{50}(\mathrm{cGy})$ & 4588 & 4557 & 4552 \\
& $\mathrm{D}_{2}(\mathrm{cGy})$ & 4660 & 4754 & 4728 \\
& $\mathrm{CI}$ & 1.85 & 0.83 & 0.89 \\
Mesane & $\mathrm{HI}$ & 0.05 & 0.09 & 0.08 \\
& $\mathrm{D}_{\text {ortalama }}$ & 4370 & 3536 & 3321 \\
& $\mathrm{~V}_{30}$ & 4524 & 4097 & 3827 \\
& $\mathrm{~V}_{45}$ & 4495 & 3843 & 3406 \\
Rektum & $\mathrm{V}_{50}$ & 4483 & 3719 & 3285 \\
& $\mathrm{D}_{\text {ortalama }}$ & 4214 & 3478 & 3247 \\
& $\mathrm{~V}_{30}$ & 4593 & 4087 & 4010 \\
& $\mathrm{~V}_{45}$ & 4505 & 3888 & 3673 \\
Sağ Femur & $\mathrm{V}_{50}$ & 4467 & 3803 & 3394 \\
& $\mathrm{D}_{\text {ortalama }}$ & 1928 & 1806 & 1263 \\
& $\mathrm{D}_{\text {mak }}$ & 4408 & 3850 & 3270 \\
& $\mathrm{~V}_{20}$ & 2548 & 2315 & 2269 \\
Sol Femur & $\mathrm{D}_{\text {ortalama }}$ & 2180 & 1824 & 1259 \\
& $\mathrm{D}_{\text {mak }}$ & 4501 & 4057 & 3233 \\
Bağırsak & $\mathrm{V}_{20}$ & 2612 & 2310 & 2274 \\
& $\mathrm{D}_{\text {ortalama }}$ & 3079 & 2553 & 2548 \\
\hline
\end{tabular}

Tablo 3. TPS ve TLD doz ölçümlerinin istatistiksel karşılaştırması

\begin{tabular}{lllll}
\hline Konum & & FIF/ & FIF/ & 5 A/ \\
& & 5A & $\mathbf{7 A}$ & 7 A \\
\hline Sağ meme & Sol & 0.059 & $\mathbf{0 . 0 0 0}$ & $\mathbf{0 . 0 0 2}$ \\
& Sağ & $\mathbf{0 . 0 0 0}^{*}$ & $\mathbf{0 . 0 0 8}^{*}$ & $\mathbf{0 . 0 3 0}^{*}$ \\
& Üst & $\mathbf{0 . 0 0 0}^{*}$ & $\mathbf{0 . 0 0 0}^{*}$ & $\mathbf{0 . 0 0 0}^{*}$ \\
& Alt & $\mathbf{0 . 0 0 0}^{*}$ & $\mathbf{0 . 0 0 0}^{*}$ & $\mathbf{0 . 0 0 0}^{*}$ \\
& Merkez & 0.317 & $\mathbf{0 . 0 0 0}^{*}$ & $\mathbf{0 . 0 0 0}^{*}$ \\
& Ortalama doz & $\mathbf{0 . 0 0 0}^{*}$ & $\mathbf{0 . 0 0 0}^{*}$ & $\mathbf{0 . 0 0 0}^{*}$ \\
Sol meme & Sol & $\mathbf{0 . 0 0 0}^{*}$ & $\mathbf{0 . 0 0 0}^{*}$ & $\mathbf{0 . 0 0 0}^{*}$ \\
& Sağ & $\mathbf{0 . 0 0 4}^{*}$ & $\mathbf{0 . 0 0 0}^{*}$ & $\mathbf{0 . 0 0 0}^{*}$ \\
& Üst & $\mathbf{0 . 0 3 6}^{*}$ & $\mathbf{0 . 0 0 1}^{*}$ & $\mathbf{0 . 0 0 7}^{*}$ \\
& Alt & $\mathbf{0 . 0 0 0}^{*}$ & $\mathbf{0 . 0 0}^{*}$ & $\mathbf{0 . 0 0 0}^{*}$ \\
& Merkez & $\mathbf{0 . 0 0 8}^{*}$ & $\mathbf{0 . 0 0 0}^{*}$ & $\mathbf{0 . 0 0 0}^{*}$ \\
& Ortalama doz & $\mathbf{0 . 0 0 0}^{*}$ & $\mathbf{0 . 0 0 0}^{*}$ & $\mathbf{0 . 0 0 0}^{*}$ \\
Tiroid & Ortalama doz & $\mathbf{0 . 0 0 0}^{*}$ & $\mathbf{0 . 0 0 0}^{*}$ & $\mathbf{0 . 0 0 0}^{*}$ \\
\hline
\end{tabular}

\subsection{Tartışma}

Radyoterapide modern tedavi tekniklerinin uygulanması, risk altındaki organların dozunu en aza indirirken, hedef hacimde yüksek dozlara çıkılmasına olanak sağlamıştır. Bu gelişmelere rağmen, radyoterapide alan dışı dozlarla ilgili kaygı devam etmektedir. Alan dışı dozdaki artış radyoterapiye bağlı ikincil kanser risklerinin artışına neden olabilmektedir. $\mathrm{Bu}$ çalışmada insan benzeri Alderson rando fantom üzerinde sanal olarak oluşturulmuş, postoperatif evre II endometrium kanseri için FIF, 5A-YART ve 7A-YART tedavi tekniklerinin meme dokusunda oluşturdukları alan dışı dozlar TLD-100 ile ölçülmüş ve TPS' den gelen doz değerleri ile karşılaştırılmıştır. TLD'lerin hassasiyetinin yüksek ve kullanım skalasının geniş olması, düşük radyasyon dozlarını ölçebilmesi, yoğunluğunun doku yoğunluğuna eşdeğer olması, boyutlarının küçük olması ve ölçülen dozu uzun süre saklayabilmesi gibi avantajları vardır. Çalışmamızla birebir örtüşen makaleye litaretürde rastlanamamıştır.

e-ISSN: 2148-2683
Cyriac ve ark. (13) Elektra marka Synergy platform medikal hızlandırıc1 (Elekta, İngiltere) cihazının, Oncentra TPS kullanarak yaptıkları çalışmada, TPS' in alan dişı doz doğruluğunu TLD kullanarak incelemişlerdir. Cyriac ve ark. hedef hacim kenarında TPS ve TLD ölçümleri arasında önemli bir fark bulunmadığı bildirmişlerdir. Ancak alan kenarından 2 cm' den 7.5 cm' ye kadar olan uzaklıklarda yaptıkları ölçümlerde, TPS ve TLD doz değerleri arasındaki farkın \%10' dan \%60 kadar arttığını göstermişlerdir. Bizim çalışmamızda alan kenarından $18 \mathrm{~cm}$ uzaklıkta bulunan meme dokusu için TPS' de 0 cGy bulunmuştur. Farklı tedavi tekniklerinde sağ meme için TLD ile ölçülen doz değerleri ortalaması FIF, 5AYART ve 7A-YART tekniklerinde sirasiyla, $20.60 \pm 0.26 \mathrm{cGy}$, $23.32 \pm 0.16$ cGy ve $27.11 \pm 0.28$ cGy olarak bulunmuştur. Sol meme için ise TLD doz ölçümleri ortalaması FIF, 5A-YART ve 7A-YART tekniklerinde sirasiyla, $20.17 \pm 0.13 \mathrm{cGy}, 22.35 \pm 0.18$ cGy ve $26.13 \pm 0.10$ cGy olarak ölçülmüştür.

Abdelaal ve ark. (14) radyoterapide dozimetrik ölçümler için sıklıkla tercih edilen Markus iyon odası dedektörünü kullanarak alan dışı dozun alan boyutu, derinlik ve uzaklık ile değişismini incelemişlerdir. Yapılan ölçümlerde farklı derinliklerde ve uzaklıklarda iyon odası ile doz saptanırken , aynı noktalarda TPS'in alan dışı doz hesaplamasında başarısız olduğunu belirtmişlerdir. Çalışmamız Abdelaal ve ark. ile paralel sonuçlar vermiştir. Endometrium alan kenarından $23 \mathrm{~cm}$ uzaklıkta bulunan tiroid için TPS ortalama doz değeri 0 cGy iken TLD ile ortalama doz ölçümlerinde FIF, 5A-YART ve 7AYART teknikleri için sırasıyla, $18.53 \pm 0.49 \mathrm{cGy}, 11.20 \pm 0.70 \mathrm{cGy}$ ve $11.10 \pm 0.12$ cGy olarak bulunmuştur.

Majer ve ark. (15) yoğunluk ayarlı radyoterapi (YART) ve üç boyutlu konformal radyoterapi (3BKRT) beyin tümörünü simüle ederek antropomorfik pediatrik fantomlarda alan dışı organ dozlarını TLD ile ölçmüşlerdir. Majer ve ark. YART ve 3BKRT tedavi tekniklerini kullanarak yaptıkları çalışma sonucunda TPS tarafından hesaplanan alan dışı dozların her iki teknik için de eksik olduğunu göstermişlerdir. Bizim araştırmamızda TPS' in alan dışı meme hacimleri için 0 cGy doz hesaplamasına rağmen TLD ölçümlerinde üç farklı teknik için de her iki meme ve tiroidin aslında doz aldığı bulunmuştur.

Sungkoo ve ark. (16) radyoterapi sonrası ikincil kanser riskinin önemli bir konu haline geldiğini belirterek, 3BKRT ve YART tedavi teknikleriyle kanser hastalarının ortalama hayatta kalma süresinin arttığını ve ikincil kanser riskinin öneminin aynı şekilde arttığını ifade etmişlerdir. 6 ve $10 \mathrm{MV}$ enerjili X-ışını kullanarak yaptıkları prostat radyoterapi ölçümlerinde, fraksiyon dozu 2 Gy için meme dozunu 0,7 cGy - 0,9 cGy aralığında bulmuşlardır. 1.8 Gy fraksiyon dozu ile yapılan endometrium 1şınlaması için ortalama TLD ölçümleri sağ memede $0.8 \mathrm{cGy}-$ 1.08 cGy aralığında, sol memede $0.80 \mathrm{cGy}-1.05$ cGy aralığında ölçülmüştür.

Jia ve ark. (17) serviks kanseri için IMRT tekniği ile 6-MV enerji ile insan benzeri bir fantomu 1şınlarken iyonizasyon odasını kullanarak meme dokusu dozunu ölçmüşlerdir. Toplam meme dozunu 22,6 cGy olarak bulmuş olup sonuçlar çalışmamızla uyumludur.

\section{Sonuç}

Jinekolojik kanser grubunda başlıca endometrium, serviks ve over kanserleri yer alır. Bu kanserler arasında en sik 
endometrium kanseri görülmektedir. Endometrium kanseri radyoterapisinde en uygun tedavi tekniği seçilirken alan diş1 dozlara dikkat edilmelidir. Ayrıca TPS' in alan kenarından uzaklaştıkça dozları doğru tahmin etmede yetersiz kaldığı göz önünde bulundurulmalıdır.

\section{Kaynakça}

Hanna, T.P., Delaney, G.P. \& Barton M.B. (2016). The population benefit of radiotherapy for gynaecological cancer: Local control and survival estimates. Radiotherapy and Oncology, 120(3), 370-377.

Aras, S. (2021). Effect of Flattening Filter and Flattening Filter Free beams on radiotherapy-induced peripheral blood cell damage. Radiat Phys Chem, 182.

Krishnan, J., Shetty, J., Rao, S., Hegde, S. \& Shambhavi, C. (2017). Comparison of Rapid Arc and Intensity-modulated Radiotherapy Plans Using Unified Dosimetry Index and the Impact of Conformity Index on Unified Dosimetry Index Evaluation. Journal of Medical Physics, 42(1), 14-17.

Ardenfors, O., Dasu, A., Lillhok, J., Persson, L. \& Gudowska I. (2018). Out-of-field doses from secondary radiation produced in proton therapy and the associated risk of radiation-induced cancer from a brain tumor treatment. Phys Medica, 53, 129-36.

Huang, J.Y., Followill, D.S., Wang, X.A. \& Kry, S.F. (2013). Accuracy and sources of error of out-of field dose calculations by a commercial treatment planning system for intensity-modulated radiation therapy treatments. Journal of Applied Clinical Medical Physics, 14(2), 186-97.

Stern, R.L. (1999). Peripheral dose from a linear accelerator equipped with multileaf collimation. Medical Physics, 26(4), 559-63.

Kim, D.W., Chung, K., Chung, W.K., Bae, S.H., Shin, D.O., \& Hong, S. et al. (2014). Risk of secondary cancers from scattered radiation during intensity-modulated radiotherapies for hepatocellular carcinoma. Radiat Oncol, 9.

Garrett, L., Hardcastle, N., Yeo, A., Lonski, P., Franich, R. \& Kron, T. (2021). Out-of-field dose in stereotactic radiotherapy for paediatric patients. Phys Imag Radiat Onc, $19,1-5$.

Joosten, A., Bochud, F., Baechler, S., Levi, F., Mirimanoff, R.O. \& Moeckli R. (2011). Variability of a peripheral dose among various linac geometries for second cancer risk assessment. Phys Med Biol, 56(16), 5131-51.

Aras, S., Tanzer, I.O., Can, U., Sumer, E. \& Baydili, K.N. (2021). The role of melatonin on acute thyroid damage induced by high dose rate X-ray in head and neck radiotherapy. Radiat Phys Chem, 179.

Toossi, M.T.B., Soleymanifard, S., Farhood, B., Mohebbi, S. \& Davenport, D. (2018). Assessment of accuracy of out-offield dose calculations by TiGRT treatment planning system in radiotherapy. J Cancer Res Ther, 14(3), 634-9.

Gregoire, V. \& Mackie, T.R. (2011). State of the art on dose prescription, reporting and recording in Intensity-Modulated Radiation Therapy (ICRU report No. 83). Cancer Radiother. 15(6-7), 555-9.

e-ISSN: 2148-2683
Cyriac, T.S., Musthafa, M.M., Raman, R.G., Haneefa, K.A. \& Bhasi S. (2015). Out-of-field photon dosimetry study between 3-D conformal and intensity modulated radiation therapy in the management of prostate cancer. Int $\mathrm{J}$ Radiat Res, 13(2), 127-34.

Bayatiani, M.R., Fallahi, F., Aliasgharzadeh, A., Ghorbani, M., Khajetash, B. \& Seif F. (2020). Determination of effective source to surface distance and cutout factor in small fields in electron beam radiotherapy: A comparison of different dosimeters. Pol J Med Phys Eng, 26(4), 235-42.

Hauri, P. \& Schneider, U. (2019). Whole-body dose equivalent including neutrons is similar for $6 \mathrm{MV}$ and $15 \mathrm{MV}$ IMRT, VMAT, and 3D conformal radiotherapy. Journal of Applied Clinical Medical Physics, 20(3), 56-70.

Zhang, Q.B., Liu, J.B., Ao, N.J., Yu, H., Peng, Y.Y. \& Ou L.Y. et al. (2020). Secondary cancer risk after radiation therapy for breast cancer with different radiotherapy techniques. Sci Rep-Uk, 10(1).

Jia, M.X., Zhang, X., Yin, C., Feng, G., Li, N. \& Gao, S. (2014). Peripheral dose measurements in cervical cancer radiotherapy: a comparison of volumetric modulated arc therapy and step-and-shoot IMRT techniques. Radiat Oncol, 9:61. 